\title{
DEMONSTRATION OF A GLUTAMATE-PYRUVATE TRANSAMINASE SILENT ALLELE IN A JAPANESE FAMILY
}

\author{
Katsunori AKIYAMA and Kazue ABE \\ Department of Legal Medicine, Tokyo Women's Medical College, \\ Kawadacho-10, Shinjuku-ku, Tokyo 162, Japan
}

\begin{abstract}
Summary Electrophoretic examination of glutamate-pyruvate transaminase (GPT) in a Japanese mother-child pair showed an atypical segregation of the GPT allele. In further investigation of the mother-grandmother pair, the phenotypes of the GPT also showed the atypical segregation. All the other genetic blood markers examined in this family were transmitted according to Mendelian inheritance. Any variant GPT could not be detected in these samples by the polyacrylamide gel electrophoresis at acidic $\mathrm{pH}$. These results suggest that the silent allele for GPT exists in this Japanese family.
\end{abstract}

\section{INTRODUCTION}

Glutamate-pyruvate transaminase (GPT) or alanine aminotransferase [EC 2.6.1.2] catalyzes the reversible interconversion of L-alanine and $\alpha$-ketoglutamate to L-glutamate and pyruvate. This enzyme exists in both soluble (cytoplasmic) form and mitochondrial form.

The genetic polymorphism of soluble GPT in human red blood cells was first described by Chen and Giblett (1971). They presented evidence that the two common allele products, GPT* 1 and GPT*2, are detectable by starch gel electrophoresis and enzyme specific staining procedures. Electrophoretic variants of rare GPT alleles have also been detected in various human populations of different ethnic origins: GPT*3-GPT*6 (Chen et al., 1972), GPT*Im (Kömpf et al., 1974), GPT*7 (Olaisen, 1973a), GPT*8 (Santachiara Benerecetti et al., 1975) and GPT*9 (Kömpf and Ritter, 1979). Furthermore, the occurrence of GPT silent allele has been described by Spielman et al. (1973), Olaisen (1973b), Speiser and Pausch (1977), Kömpf and Ritter (1979), Mithal et al. (1980) and Maryellen et al. (1983).

In this paper, we report a GPT silent allele discovered in a Japanese family.

Received July 20, 1984; revised version received August 3, 1984 


\section{MATERIALS AND METHODS}

Sample. Blood samples were washed three times with saline, and the packed red blood cells were lysed by freezing and thawing for three times.

Starch gel electrophoresis. The GPT phenotypes were detected by starch gel electrophoresis according to the method of Kömpf and Ritter (1979). Electrophoresis was carried out for $18 \mathrm{hr}$ using a Tris-histidine- $\mathrm{HCl}$ buffer system. The gel buffer was a $1: 12$ dilution of bridge buffer $(0.2 \mathrm{~m}$ Tris and $0.17 \mathrm{~m}$ histidine, $\mathrm{pH}$ 7.6). Horizontal electrophoresis was performed at $5 \mathrm{~V} / \mathrm{cm}$ with cooling at $4^{\circ} \mathrm{C}$.

Staining method. The enzyme specific staining was carried out according to the method of Harris and Hopkinson (1976). The staining mixture consisted of $360 \mathrm{mg}$ L-alanine, $25 \mathrm{mg} \alpha$-ketoglutaric acid, $14 \mathrm{mg} \mathrm{NADH}, 8 \mathrm{U} \mathrm{LDH}$ and $25 \mathrm{ml}$ staining buffer $(0.1 \mathrm{M}$ Tris-HCl, $\mathrm{pH} 8.0)$. Whatman no. 1 filter paper saturated with staining solution was laid on the bottom half of the sliced gel, which was then incubated at $37^{\circ} \mathrm{C}$ for $4 \mathrm{hr}$. Under the UV light, zones of GPT activity appeared as dark blue spots.

\section{RESULTS AND DISCUSSION}

In paternity examinations, atypical segregation of the GPT phenotype was observed between the mother(II-2) and the chold(III-1) in one case: The mother's phenotype was GPT 1 and the child's phenotype was GPT 2, as shown in Fig. 1. To examine the maternity, we analyzed the other genetic blood markers of the

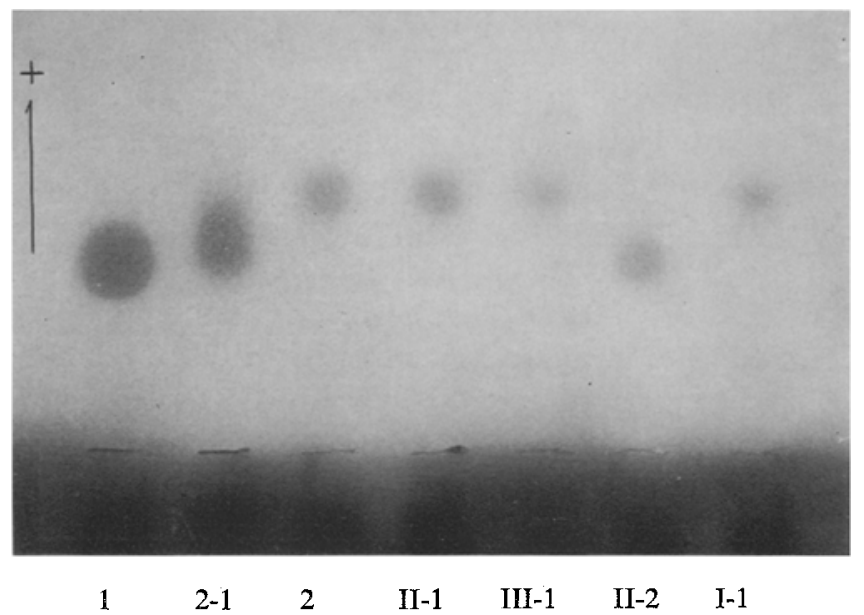

Fig. 1. Electrophoretic patterns of GPT isozymes in starch gel electrophoresis. 1, 2-1, and 2: standard samples for GPT 1, 2-1 and 2, respectively. II-1, III-1, II-2, and I-1: samples from the father, child, mother, and grandmother, respectively. 


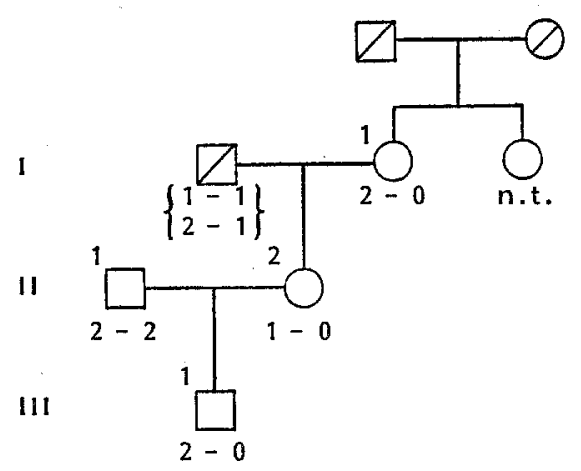

Fig. 2. Pedigree chart of the family showing the atypical segregation of the red blood cell GPT phenotype.

Table 1. Genetic blood markers in the family members.

\begin{tabular}{|c|c|c|c|c|c|c|c|c|c|c|}
\hline & $\mathrm{ABO}$ & MNSs & $\mathrm{Rh}$ & \multicolumn{2}{|c|}{ Fy } & $\mathrm{Jk}$ & $\mathrm{Le}$ & Kell & $\mathrm{P}$ & AcP \\
\hline I-1 & B & Nss & CcDee & \multicolumn{2}{|c|}{$a+b-$} & $a-b+$ & $a+b-$ & $\mathbf{K}-\mathbf{k}+$ & $\mathbf{P}_{\mathbf{I}}^{-}$ & BA \\
\hline II-1 & A & MNss & $\mathrm{CcDEe}$ & \multicolumn{2}{|c|}{$a+b-$} & $a+b+$ & $a-b+$ & $\mathbf{K}-\mathbf{k}+$ & $\mathbf{P}_{1}^{-}$ & $\mathrm{B}$ \\
\hline II-2 & o & MNss & $\operatorname{ccDEe}$ & \multicolumn{2}{|c|}{$a-b-$} & $a-b+$ & $a+b-$ & $\mathbf{K}-\mathrm{k}+$ & $\mathrm{P}_{1}^{-}$ & B \\
\hline III-1 & $\mathrm{O}$ & Nss & $\mathrm{CcDEe}$ & \multicolumn{2}{|c|}{$a+b-$} & $a+b+$ & $a-b+$ & $\mathrm{K}-\mathrm{k}+$ & $\mathrm{P}_{1}^{-}$ & B \\
\hline & PGM & PGD & GPT & EsD & GLO & $\mathrm{ADA}$ & FUC & GDH & $\mathrm{Gm}$ & $\mathrm{Km}$ \\
\hline I-1 & $2 \mathrm{~A}$ & A & 2 & 1 & 2 & 1 & $2-1$ & 1 & $1,-2,-12$ & -1 \\
\hline II-1 & $1 \mathrm{~A}$ & A & 2 & $2-1$ & $2-1$ & 1 & $2-1$ & 1 & $1,-2,-12$ & 1 \\
\hline II-2 & $1 \mathrm{~A} 2 \mathrm{~A}$ & A & 1 & $2-1$ & $2-1$ & 1 & $2-1$ & $2-1$ & $1,-2,-12$ & -1 \\
\hline III-1 & $1 \mathrm{~A} 2 \mathrm{~A}$ & A & 2 & 2 & $2-1$ & 1 & $2-1$ & 1 & $1,-2,-12$ & 1 \\
\hline & $\mathrm{Hp}$ & Gc & F-XIIIA & \multicolumn{2}{|c|}{ F-XIIIB } & $\mathrm{Tf}$ & $\mathrm{Pi}$ & & & \\
\hline I-1 & 2 & 1F-1S & 1 & \multicolumn{2}{|c|}{$1-3$} & $\mathrm{C} 1$ & M1M1 & & & \\
\hline II-1 & 2 & 2 & 1 & \multicolumn{2}{|c|}{3} & $\mathrm{C} 1$ & $\mathrm{M} 1 \mathrm{M} 2$ & & & \\
\hline $\mathrm{II}-2$ & 2 & $1 F-1 S$ & 1 & \multicolumn{2}{|c|}{3} & $\mathrm{C} 1$ & M1M2 & & & \\
\hline \multirow[t]{2}{*}{ III-1 } & 2 & $2-1 F$ & 1 & 3 & & $\mathrm{C} 1$ & $2 \mathrm{M} 2$ & & & \\
\hline & $\mathrm{HL}$ & system & & & & & & & & \\
\hline I-1 & $\mathrm{A} 2$ & Aw33 & Bw6 & & $3 w 44$ & $\mathrm{Cw}-$ & & & & \\
\hline II-1 & $\mathrm{A} 2$ & Aw31 & Bw5 & & Bw- & Cw3 & & & & \\
\hline II -2 & Aw26 & Aw33 & $\mathrm{Bw} 3 \mathrm{~s}$ & & 3w44 & $\mathrm{CW}_{\mathrm{W}}$ & & & & \\
\hline III-1 & $\mathrm{A} 2$ & Aw33 & Bw5 & & $3 w 44$ & $\mathrm{Cw} 3$ & & & & \\
\hline
\end{tabular}


mother(II-2) and the child(III-1), including those of the accused father(II-1) (Fig. 2). These included ABO, MNSs, Rh, Duffy, Kidd, Lewis, Kell, and $P$ in red blood cell antigens, AcP, PGM, PGD, GPT, EsD, GLO, and ADA in red blood cell isozymes, FUC and GDH in white blood cell isozymes, $\mathrm{Gm}, \mathrm{Km}, \mathrm{Hp}, \mathrm{Gc}$, Factors $\mathrm{XIII} \mathrm{A}$ and $\mathrm{B}, \mathrm{Tf}$, and $\mathrm{Pi}$ in plasma proteins, and the $\mathrm{A}, \mathrm{B}$ and $\mathrm{C}$ antigens of the HLA system. In all these genetic markers, contradictable combinations were not found between the mother(II-2) and the child(III-1), and also between the accused father(II-1) and the child(III-1), indicating that both the mother(II-2) and the accused father(II-1) are his real parents (Table 1). Since these findings suggested that a GPT silent allele exists in the mother(II-2) and her son(III-1), we further examined the genetic blood markers of the grandmother(I-1).

As shown in Fig. 1, the GPT staining intensity of the child(III-1), the mother(II2) and the grandmother(I-1) were very weak compared with controls, suggesting a decrease in the activity of the GPT isozymes in these family members. In addition, the atypical segregation of the GPT phenotype was also observed between the mother and the grandmother, though in the other genetic markers, contradictable genetic combinations were not found (Fig. 1 and Table 1). McLellan (1982) showed that the GPT 2 type consists of the GPT 2A and the GPT 2B using the polyacrylamide gel electrophoresis at acidic $\mathrm{pH}$. We examined the GPT types of these samples using the same electrophoretic method, but the variant of GPT could not be detected.

These results indicate that the child, mother and grandmother in this Japanese family have a GPT silent alle. It is very likely that a decrease in the GPT activity in the child, mother and grandmother is due to a gene dosage effect.

\section{REFERENCES}

Chen, S.H. and Giblett, E.R. 1971. Polymorphism of soluble glutamic pyruvic transaminase. Science 173: 148-149.

Chen, S.H., Giblett, E.R., Anderson, J.E., and Fossum, B.L.G. 1972. Genetics of glutamic-pyruvic transaminase: its inheritance, common and rare variants, population distribution, and differences in catalytic activity. Ann. Hum. Genet. 35: 401-409.

Harris, H. and Hopkinson, D.A. 1976. Handbook of Enzyme Electrophoresis in Human Genetics, North-Holland, Amsterdam,

Kömpf, J., Bissbort, S., Ritter, H., and Wendt, G.G. 1974. The polymorphism of alanine aminotransferase [E.C. 2.6.1.2]: Densitometrical assay. Hum. Genet. 22: 247-249.

Kömpf, J. and Ritter, H. 1979. Polymorphism of alanine aminotransferase [E.C. 2.6.7.1]: Common and rare alleles. Hum. Genet. 51: 287-292.

Maryellen, C.S., Crist, M., and Sparkes, R.S. 1983. Glutamate pyruvate transaminase null allele in seven new families. Hum. Genet. 65: 147-148.

McLellan, T. 1982. Two previously undetected variants of glutamic-pyruvic transaminase found by acidic polyacrylamide gel electrophoresis. Am. J. Hum. Genet. 34: 623-629.

Mithal, Y., Lane, A.B., and Jenkins, T. 1980. Absence of red cell glutamate-pyruvate transaminase: Discovery of a "silent" allele homozygote. Am. J. Hum. Genet. 32: 42-46.

Olaisen, B. 1973a. Two rare GPT phenotypes in a Norwegian family. Evidence of a seventh allele. Humangenetik 19: 289-291. 
Olaisen, B. 1973b. Atypical segregation of erythrocyte glutamic-pyruvic transaminase in a Norwegian family. Hum. Hered. 23 : 595-602.

Santachiara Benerecetti, A.S., Beretta, M., and Pampiglione, S. 1975. Red cell glutamic-pyruvic transaminase polymorphism in a sample of the Italian population. A new variant allele: GTP'. Hum. Hered. 25: 276-278.

Speiser, P. and Pausch, V. 1977. GPT ${ }^{0}$ in drei Generationen. (Evidence of GPT ${ }^{0}$ segregation in three generations.) Ärztl. Lab. 23: 487-490.

Spielmann, W., Kühnl, P., Rexrodt, Ch., and Hänsel, G. 1973. Untersuchungen zum GPT-System unter besonderer Berücksichtigung des stummen Allels GPT ${ }^{0}$. Humangenetik 18: 341-348.

Vol. 29, No. 3, 1984 